\title{
DOS NUEVAS ESPECIES DE CROTON (EUPHORBIACEAE) EN EL NEOTRÓPICO
}

\author{
José GonzÁlez Ramírez y Luis Poveda Álvarez² \\ ${ }^{1}$ Instituto Nacional de Biodiversidad (INB). Apdo. 22-3100, Santo Domingo, Heredia, Costa Rica. \\ jgonzal@inbio.ac.cr \\ ${ }^{2}$ Herbario Juvenal Valerio (JVR), Universidad Nacional de Costa Rica. Apdo. 86-3000, Heredia, Costa Rica. \\ lpoveda@una.ac.cr
}

\begin{abstract}
Two new species of Croton L. (Euphorbiaceae) restricted to Costa Rica are described and illustrated in this paper: Croton corinthius from the lowlands of the Caribbean slope and Croton megistocarpus from the midlands of both slopes of the main ridges. The first is distinguished for the presence of stalked glands near the vein axils of the leaves. The second is compared to C. pachypodus Webster, from Panama and Colombia.

Resumen. Se describen e ilustran dos nuevas especies de Croton L. (Euphorbiaceae) restringidas a Costa Rica: Croton corinthius, de las tierras bajas de la vertiente Caribe, y Croton megistocarpus, de las tierras medias en ambas vertientes de las principales cordilleras. La primera se distingue por la presencia de glándulas pedunculadas cerca de las axilas de los nervios secundarios de las hojas. La segunda se compara con C. pachypodus Webster, de Panamá y Colombia.
\end{abstract}

Palabras clave / Key words: Euphorbiaceae, Croton corinthius, Croton megistocarpus, Costa Rica.

El género Croton cuenta con alrededor de 800 especies, distribuidas en los trópicos y subtrópicos del mundo (Burger 1995). En Costa Rica representa aproximadamente el $20 \%$ de las especies nativas de la familia Euphorbiaceae (González, en preparación). Se trata de árboles (19 especies), arbustos (7 especies) y hierbas (5 especies). Pertenece a la subfamilia Crotonoideae Pax (Webster 1994), que se caracteriza por tener 1 óvulo en cada lóculo, savia coloreada, rojiza o blanquecina, indumento simple, dendrítico, estrellado o lepidoto, flores con los sépalos encerrando completamente las anteras y los granos de polen tricolporados, porados o inaperturados. Además, Croton se ubica en la tribu Crotoneae Dumort, distintiva por presentar estípulas, granos de polen inaperturados, semillas con endospermo, indumento de tricomas lepidotos o estrellados y frutos capsulares.

Croton corinthius Poveda \& J. A. González, sp. nova TIPO: Costa Rica. Limón: Pococí, Guápiles, Centro Ecológico Morpho, márgenes del Río Corinto, $10^{\circ} 11^{\prime} 55^{\prime \prime} \mathrm{N}, 83^{\circ} 54^{\prime} 25^{\prime \prime} \mathrm{W}, 210 \mathrm{~m}, 3$ mayo 1995 (fl,fr), J. González et al. 725 (holotipo, INB; isotipos, B, CAS, CR, F, K, MEXU, MO, USJ).

Arbor vel frutex, 4-10 m alta, foliis (7)15-17(30) cm longis, (3)5-8(15) cm latis, alternis vel suboppositis, lanceolatis vel ellipticis. Floribus imperfectis. Capsulis 10-13 mm latis.

Árbol o arbusto, 4-10 m de altura; monoico; indumento de tricomas estrellados, grisáceos o ferrugíneos. Estípulas 3-6 x 0,2--0,4 mm, lineares, cubiertas por tricomas estrellados. Hojas 7-30 × 3-15 cm, alternas o sub-opuestas, pecíolos con dos glándulas laterales pedunculadas en el ápice, de 0,3-0,8 $\mathrm{mm}$ de diámetro, sésiles o con pedicelos de $0,3-0,7 \mathrm{~mm}$, a veces con 2 glándulas en el ápice de $0,3 \mathrm{~mm}$ de diámetro. Lámina foliar lanceolada a elíptica, ápice acuminado, base aguda a redondeada, margen subentero o con pocos dientes, el haz diminutamente pustulado, tricomas estrellados esparcidos por toda la lámina, concentrándose más en el nervio central y los secundarios, el envés pustulado, tricomas estrellados esparcidos uniformemente en los nervios terciarios, más densos en el nervio central y en los secundarios, glándulas pedunculadas $0,1-0,5 \mathrm{~mm}$ de diámetro, con pedicelos proporcionales al diámetro, ubicadas mayormente cerca de la confluencia de los nervios terciarios con los secundarios y de éstos con el central. Con 3 nervios en la base, 7-13 adicionales a cada lado del nervio central. Inflorescencia $15-40 \mathrm{~cm}$ de 

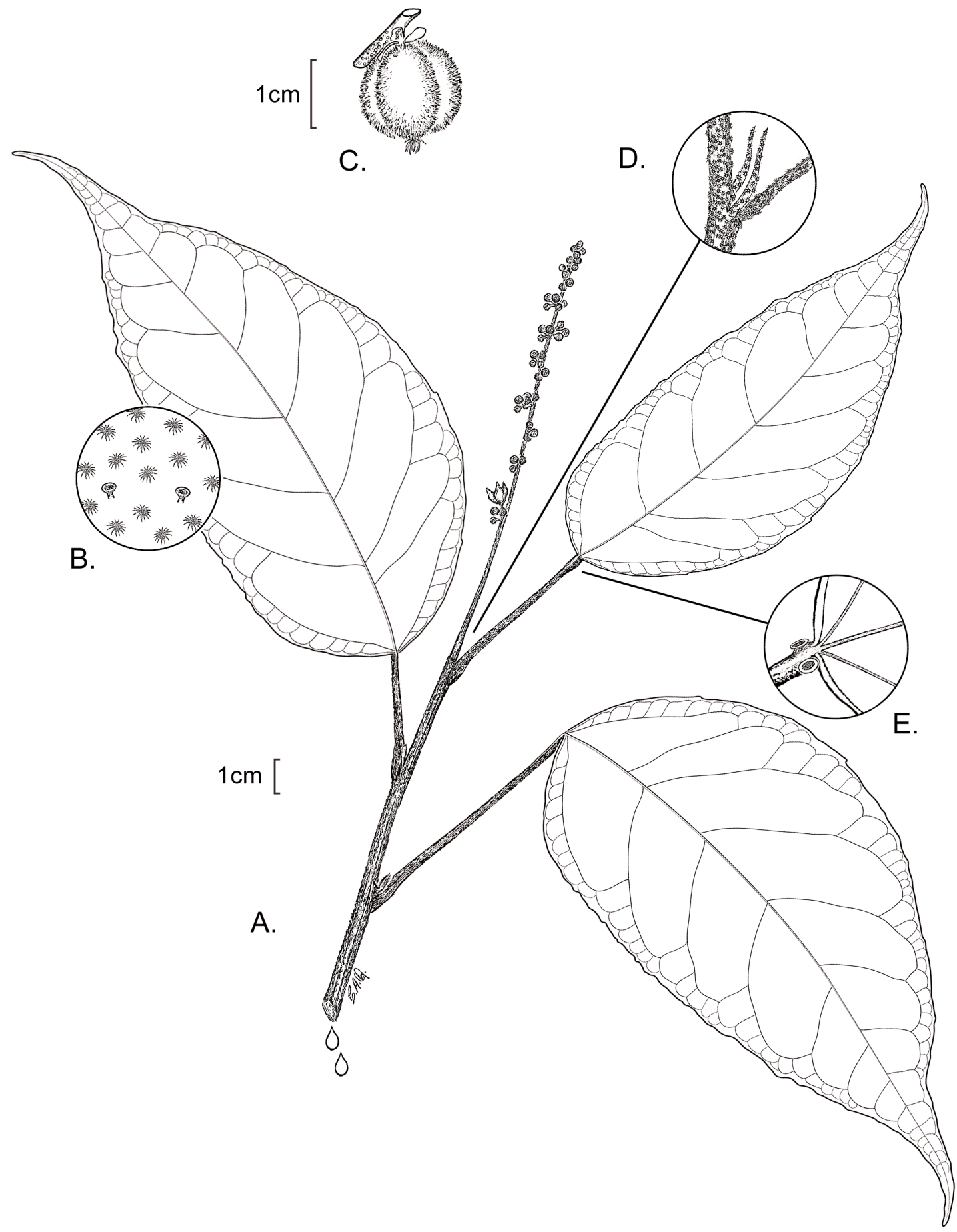

Figura 1. Croton corinthius Poveda \& J. A. González. A. Ramita florida. B. Detalle de glándulas pedunculadas en el envés de la lámina (x 2). C. Fruto. D. Detalle de las estípulas (x 3). E. Detalle de las glándulas del pecíolo (x 2). TESTIGO DE LA ILUSTRACIÓN: J. González et al. 725 (INB). 
largo, terminal, racemosa; flores en fascículos, con 1 flor pistilada y (1)4-5 flores estaminadas; flores estaminadas con pedicelos de $1-5 \mathrm{~mm}$, cubiertos por tricomas estrellados; sépalos 5, ca. $2 \times 2 \mathrm{~mm}$, unidos en la base, valvados, triangular-ovados, cubiertos externamente por tricomas estrellados e internamente por tricomas simples; pétalos 5, 2,5 x 0,9-1,5 mm, imbricados, oblongo-obovados, externamente glandulares, internamente lisos, con el margen densamente cubierto por tricomas simples; estambres 16, filamentos 1$1,8 \mathrm{~mm}$, glabros; anteras $0,9 \mathrm{~mm}$, glabras; disco con 5 lóbulos glandulares; flores pistiladas con pedicelos de 2-3 mm; cubiertos por tricomas estrellados; sépalos 5, $2,7 \times 1,5 \mathrm{~mm}$, unidos en la base, valvados, triangularovados; cubiertos externamente por tricomas estrellados e internamente por tricomas simples; pétalos 0 ; disco con 5 glándulas; ovario cubierto por tricomas estrellados; estilo ca. $3 \mathrm{~mm}$, unido sobre la superficie del ovario, 2-3 veces dividido (con 4-6 segmentos). Cápsulas 10-13 mm, esféricas, densamente cubiertas por diminutos tricomas estrellados, columnela $c a .11$ $\mathrm{mm}$; semillas $11 \times 6 \mathrm{~mm}$, tetragonales, glabras, pardas con manchas oscuras, superficie con estrías cortas, carúncula ca. 1 × 0,9 mm.

DISTRIBUCIÓN Y HÁBITAT: Croton corinthius está restringido a las llanuras de Tortuguero, en la vertiente Caribe de Costa Rica, específicamente en el cantón de Pococí, provincia de Limón. Crece en bosques muy húmedos entre 50 y $210 \mathrm{~m}$ de altitud, prefiriendo aparentemente la proximidad de los ríos. En la localidad tipo crece junto con Quararibea cordata (Bonpl.) Vischer (Bombacaceae), Croton billbergianus Müll. Arg. (Euphorbiaceae), Dalbergia melanocardium Pittier, Pterocarpus officinalis Jacq. (Fabaceae/Pap.), Guarea guidonia (L.) Sleumer (Meliaceae), Colubrina spinosa Donn. Sm. (Rhamnaceae) y Heliocarpus appendiculatus Turcz. (Tiliaceae), entre otras especies.

ETIMOLOGíA: El epíteto hace mención al Río Corinto, en cuyas márgenes esta especie fue recolectada por primera vez.

Croton corinthius es una especie muy distintiva por poseer glándulas pedunculadas diminutas (observables a 10x) en el envés, característica que en el país sólo comparte con Croton smithianus Croizat (con glándulas en el haz y el envés). Croton smi- thianus posee, además, hojas lobuladas (enteras en $C$. corinthius) y flores estaminadas con 10-12 estambres (16 en C. corinthius).

Croton corinthius pertenece a la sección Cyclostigma (Webster 1993), que se distingue por el indumento compuesto por tricomas estrellados, inflorescencias terminales, con las címulas basales bisexuales, flores estaminadas diclamídeas, con 11-110 estambres, las pistiladas apétalas. Se ubica en la subsección Cyclostigma (loc. cit.), distintiva por tener flores estaminadas con 15 a 65 estambres y flores pistiladas con estilos bífidos.

Burger \& Huft (1995) incluyeron esta especie como Croton sp. A en el tratamiento de la familia para Costa Rica.

PARATIPOS: Costa Rica. Limón: Pococí, Finca La Suerte, 10²6'30' 'N, 8347'20' 'W, $50 \mathrm{~m}, 8$ julio 1995 (fl), R. Aguilar 4192 (CR, INB, MO, USJ).

Croton megistocarpus J. A. González \& Poveda, $s p$. nova

TIPO: Costa Rica. San José: Puriscal, San Martín, bosque primario remanente en la fila Vara Blanca, cabeceras del Río Negro, límite NO de La Cangreja, 0944'02”N, 84²3'32”'W, 800-950 m, 21 abril 1995 (fl), J. F. Morales 3915 (holotipo, INB; isotipos, CR, $\mathrm{F}, \mathrm{K}, \mathrm{MO})$.

Arbor 8-30 m alta, foliis 2-13 cm longis, 1,5-6 cm latis, alternis, ellipticis, ovatis vel obovatis. Floribus imperfectis. Capsulis 3,5-4(5) cm longis, 3-4 cm latis.

Árbol de 8-30 m de altura; monoico; indumento de tricomas escamosos. Estípulas 3-6 x 0,2-2 mm, subuladas o espatuladas, cubiertas por tricomas escamosos. Hojas alternas, pecíolos levemente acanalados, con 2 glándulas pedunculadas en el ápice, orientadas hacia el envés, de ca. 0,5-1,5 mm. Lámina foliar 2-13 x 1,5-6 cm, elíptica, elíptico-ovada a obovada, con 5-10 nervios secundarios a cada lado de la costa central; ápice acuminado a abruptamente acuminado, algunas veces obtuso, base aguda a redondeada, margen diminutamente crenado-aserrado, el haz glabro o con tricomas escamosos esparcidos, el envés densamente cubierto por tricomas escamosos. Inflorescencia 2-12 cm, terminal, racemosa; flores pistiladas solitarias en la base, las estaminadas en fascículos distales o una flor pistilada y 


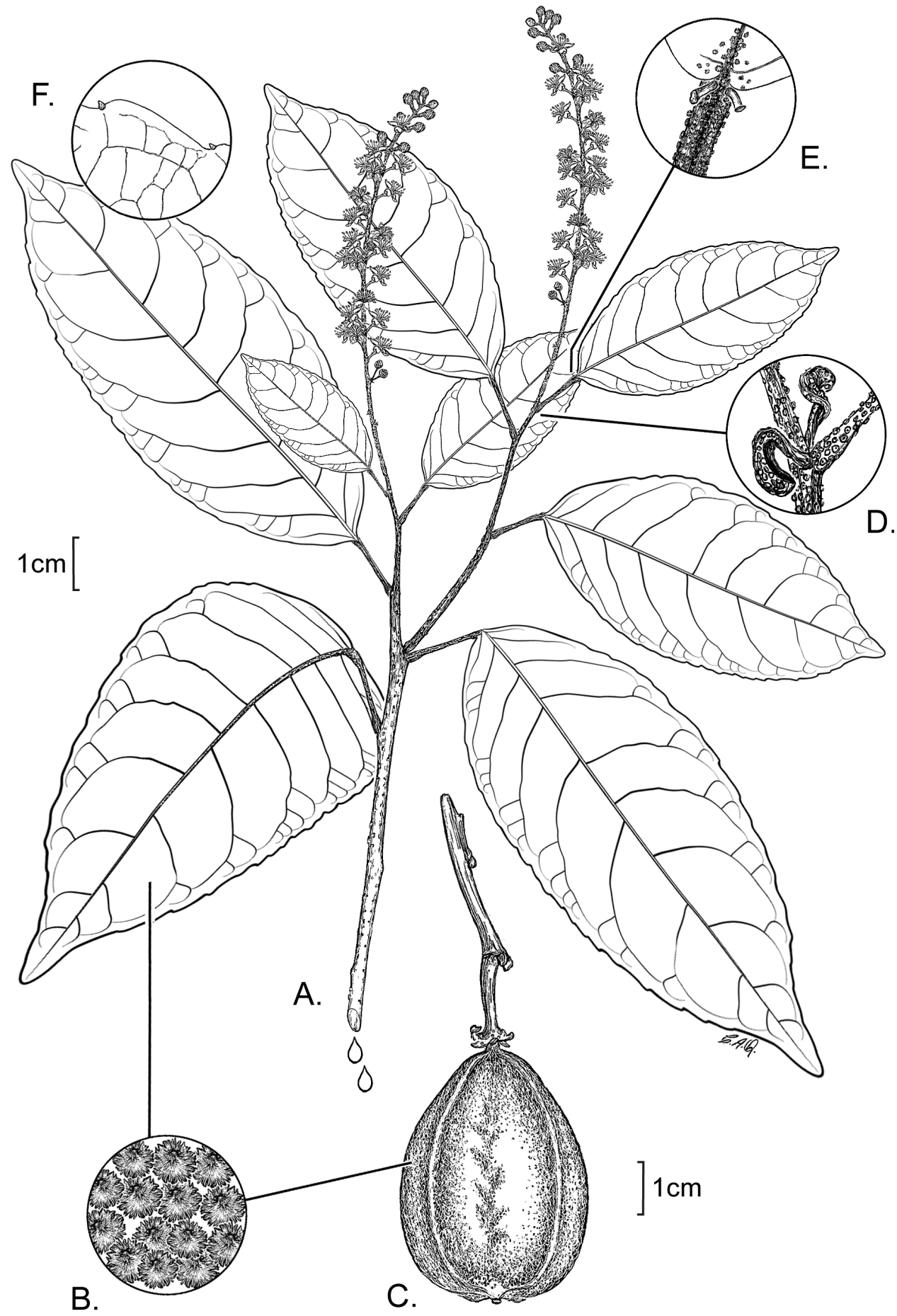

Figura 2. Croton megistocarpus J. A. González \& Poveda. A. Ramita florida. B. Detalle de tricomas lepidotos (x 10). C. Fruto. D. Detalle de las estípulas (x 2). E. Detalle de glándulas en el pecíolo (x 2). F. Detalle de dientes marginales (x 3 ). TESTIGO DE LA ILUSTRACIÓN: J. F. Morales 3915 (INB). 
varias flores estaminadas en el mismo nudo; flores estaminadas con pedicelos de 3-6 mm; sépalos 5, ca. $3 \times 1,5 \mathrm{~mm}$, unidos en la base, valvados, elípticos o elíptico-ovados, cubiertos externamente por tricomas escamosos e internamente por tricomas simples o ramificados; pétalos 5, 2,5 × $1 \mathrm{~mm}$, libres, lineares, el margen conspicuamente cubierto por tricomas estrellados o ramificados; estambres 15-16, filamentos 2,5$-3 \times 0,3-0,4 \mathrm{~mm}$, glabros; anteras $0,9 \times 0,5 \mathrm{~mm}$, glabras; disco $c a$. 2,5 $\mathrm{mm}$ de diámetro; flores pistiladas con pedicelos de 1-4 mm, sépalos 5, 2,5 × 2 $\mathrm{mm}$, unidos en la base, valvados, triangular-ovados, cubiertos externamente por tricomas escamosos e internamente por tricomas estrellados o ramificados; pétalos 0 ; disco $c a$. $2,5 \mathrm{~mm}$ de diámetro; ovario cubierto por tricomas escamosos; estilos de $c a .3 \mathrm{~mm}$, libres, estigmas bífidos distalmente. Cápsulas 3,5-5 x 3-4 cm, oblatas o piriformes, con la superficie cubierta por tricomas escamosos; semillas 2,1-2,4 x 1,5-1,6 $\mathrm{cm}$, sub-reniformes, glabras, pardas, carúncula $0,35 \times$ $0,25 \mathrm{~cm}$, en forma de $\mathrm{V}$, inconspicuamente elevada, semejando una mancha pardo-oscura.

\section{DISTRIBUCIÓN Y HÁBITAT: Croton megistocarpus} crece en los bosques húmedos premontanos de ambas vertientes de las principales cadenas montañosas del país, entre 500 y $1200 \mathrm{~m}$ de altitud. Usualmente crece junto con especies como Hyeronima alchorneoides Allemao (Euphorbiaceae), Virola koschnyi Warb., Virola sebifera Aubl. (Myristicaceae), Vochysia ferruginea Mart. y Vochysia guatemalensis Donn. Sm. (Vochysiaceae), entre otras especies.

ETIMOLOGÍA: El epíteto hace referencia al tamaño de los frutos, que son probablemente los más grandes del género Croton en el área mesoamericana.

Croton megistocarpus es una especie muy distintiva por su gran tamaño (es la especie de mayor altura que se encuentra en el país), sus hojas con el envés densamente cubierto por tricomas escamosos, sus pecíolos levemente acanalados con 2 glándulas pedunculadas en el ápice y el tamaño de sus frutos. Esta especie fue confundida anteriormente con $C$. tenuicaudatus Lundell, el cual difiere por sus pecíolos eglandulares, hojas con el borde entero y frutos más pequeños. Burger \& Huft (1995) lo trataron como $C$. pachypodus Webster, el cual tiene generalmente las hojas negras cuando secas (verdes o pardo-claro en $C$. megistocarpus), el envés esparcidamente cubierto por tricomas escamosos (densamente cubierto en $C$. megistocarpus), el margen de la lámina entero (crenado o aserrado en C. megistocarpus) y frutos que miden hasta $2,5 \mathrm{~cm}$ de longitud (hasta $5 \mathrm{~cm}$ en $C$. megistocarpus). Croton pachypodus aún no se ha recolectado en Costa Rica.

Croton megistocarpus pertenece a la sección Corylocroton (Webster 1993) que se distingue por el indumento compuesto por tricomas lepidotos, inflorescencias terminales con las címulas uni o bisexuales, flores estaminadas con 10-18 estambres y flores pistiladas apétalas con los estilos bífidos.

PARATIPOS: Costa Rica. Alajuela: San Ramón, laderas al este de la Reserva Biológica Alberto M. Brenes, $10^{\circ} 12^{\prime} 53^{\prime} \mathrm{N}, 8^{\circ} 36^{\prime} 28^{\prime \prime} \mathrm{W}, 2$ mayo 1987 (fl), G. Herrera 607 (CR, F, MO); San Ramón, Río Balsa, 7 km antes de Bajo Rodríguez, $10^{\circ} 15^{\prime} \mathrm{N}, 84^{\circ} 31^{\prime} \mathrm{W}, 500 \mathrm{~m}, 12$ julio 1991 (fr), E. Bello 1039 (CR, F, INB, MO); Bosque Eterno de Los Niños, Atlantic slope, Río Peñas Blancas Valley, Laguna Poco Sol, $10^{\circ} 21^{\prime} \mathrm{N}, 84^{\circ} 40^{\prime} \mathrm{W}, 840 \mathrm{~m}, 27$ abril 1992 (fl), Haber \& Zuchowski 11172 (CR, F, INB, MO). Guanacaste: Tilarán, rumbo a Tierras Morenas, 8 agosto 1973 (fr), L. J. Poveda 603 (CR, F, MO); 6 km north of village of Río Chiquito, disturbed premontane wet forest; slope above Lake Arenal, $10^{\circ} 25^{\prime} \mathrm{N}, 86^{\circ} 46^{\prime} \mathrm{W}, 600-700 \mathrm{~m}$, 8 May 1986 (fl), Haber et al. 4818 (CR, F, MO); Río Negro ford on south side of Lake Arenal, slope and ridges in premontane wet forest, $10 \mathrm{~km} \mathrm{NE}$ of Santa Elena, $10^{\circ} 25^{\prime} \mathrm{N}, 84^{\circ} 46^{\prime} \mathrm{W}, 600-800 \mathrm{~m}, 9$ May 1986 (fl), Haber et al 4896 (CR, F, MO); Parque Nacional Rincón de la Vieja, Hacienda Santa María, siguiendo el canal, $1 \mathrm{~km}$ sobre el mismo, partiendo de la planta hidroélectrica, $10^{\circ} 48^{\prime} \mathrm{N}$, $85^{\circ} 19$ W, 800-850 m, 6 agosto 1987 (fr), G. Herrera 648 (CR, F, MO); Parque Nacional Guanacaste, Estación Pitilla y sendero El Mismo, $10^{\circ} 59^{\prime} 26^{\prime \prime} \mathrm{N}, 85^{\circ} 25^{\prime} 40^{\prime \prime} \mathrm{W}$, 700 m, 15 junio 1991 (fl), P. Ríos 365 (CR, DAV, F, INB, MO, USJ). Puntarenas: Reserva Biológica Monteverde, Río Peñas Blancas, $10^{\circ} 18^{\prime} \mathrm{N}, 84^{\circ} 45^{\prime} \mathrm{W}, 900 \mathrm{~m}, 15$ mayo 1987 (fl), Haber \& Bello 7036 (DAV, F, MO). San José: Turrubares, Zona Protectora Turrubares, Cuenca del Río Grande de Tárcoles, Cerro Turrubares, toma de agua para Orotina, bosque húmedo, $09^{\circ} 49^{\prime} 00^{\prime \prime} \mathrm{N}, 84^{\circ} 29^{\prime} 00^{\prime} \mathrm{W}, 500-$ 1000 m, 3 abril 1993 (fl), Hammel \& Grayum 18936 (CR, $\mathrm{F}, \mathrm{INB}, \mathrm{MO})$.

\section{Agradecimientos}

Los autores desean agradecer a Michael H. Grayum por sus comentarios y sugerencias; a Andrea Albertin por la revision de los textos, y a Claudia Aragón por las ilustraciones. 


\section{LITERATURA CITADA}

Burger, W.C \& M. Huft. 1995. Euphorbiaceae. Flora Costaricensis. Fieldiana, Bot. n. s. 36.

González, J. Euphorbiaceae. In: B. E. Hammel, N. Zamora \& M. H. Grayum (eds.). Manual de Plantas de Costa Rica. Vol. 3: Dicotiledóneas. Missouri Bot. Gard. Press, St. Louis \& Inst. Nac. de Biodiversidad, Santo Domingo de Heredia, Costa Rica. (En preparación)
Webster, G.L. 1988. Revised Synopsis of Panamanian Euphorbiaceae. Ann. Missouri Bot. Gard. 75: 10871144.

Webster, G.L. 1993. A provisional synopsis of the sections of the genus Croton. Taxon 42: 793-823.

Webster, G.L. 1994. Calification of the Euphorbiaceae. Ann. Missouri Bot. Gard. 81: 3-32. 